\title{
Probiotics: An End to Caries?
}

\section{${ }^{1}$ Subija K Narayanankutty, ${ }^{2} \mathrm{~S}$ Amal, ${ }^{3}$ VG Sam Joseph, ${ }^{4}$ SG Anupama}

\section{ABSTRACT}

Probiotics have been recently introduced in dentistry and is one of the newer approaches in caries management. They have been used successfully for several years mainly for gastrointestinal disorders. Most probiotic strains belong to Lactobacilli or bifidobacteria group. Mechanism of action of probiotics is mainly unknown but may include intermicrobial species interactions and immunostimulatory effects. Randomized controlled trials have shown the inhibitory effect of probiotics against caries. Even though direct recommendations for the use of probiotics cannot yet be given, scientific evidence so far indicates that probiotic therapy may be a reality in dentistry in the future.

Keywords: Bifidobacterium, Dental caries, Lactobacillus, Probiotics.

How to cite this article: Narayanankutty SK, Amal S, Joseph VGS, Anupama SG. Probiotics: An End to Caries?. Cons Dent Endod J 2016;1(1):6-8.

Source of support: Nil

Conflict of interest: None

\section{INTRODUCTION}

Dental caries is as ancient as mankind and has the longest association with the dental profession. It is a disease not yet in our control and with still evolving management approaches. For the past 150 years we have been following the surgical approach of caries management, that is, 'drill and fill', followed by the antimicrobial model, both of which were not highly successful. ${ }^{2}$ To overcome the flaws of both these models a probiotic approach was introduced.

The word 'probiotics' derives from two Greek words meaning 'for life.' Probiotics has emerged as a health-

${ }^{1}$ Senior Resident, ${ }^{2}$ Junior Resident, ${ }^{3}$ Professor and Head ${ }^{4}$ Assistant Professor

${ }^{1}$ Department of Conservative Dentistry and Endodontics Government Dental College, Thrissur, Kerala, India

${ }^{2-4}$ Department of Conservative Dentistry and Endodontics Government Dental College, Thiruvananthapuram, Kerala, India

Corresponding Author: S Amal, Junior Resident, Department of Conservative Dentistry and Endodontics, Government Dental College, Thiruvananthapuram, Kerala, India, e-mail: amal1221986@gmail.com related and commercial target in the last two decades. Endorsed by the Food and Agriculture Organization and the World Health Organization, probiotics are defined as 'live microorganisms which when administered in adequate amounts confer health benefits on the host. ${ }^{1}$

The hypothesis of positive role of bacteria was first introduced by Ellie Metchnikoff in 1907. He found out that lactic acid bacteria has beneficial effects in human body. The term 'probiotics' was first introduced by Werner Kollat. Most of the species of bacteria with probiotic properties belong to the genera Lactobacillus and Bifidobacterium. Those bacteria are generally regarded as safe as they can reside in human body without causing any harm.

\section{Mechanism of Action}

Mechanisms of action of probiotic effects include modulation of host immune response leading to strengthening of the resistance to pathogenic challenge, alteration of the composition and metabolic activity of host microbiota at the specific location.

Probiotics should have the following properties to produce the desirable effects needed in the host:

- Adhesion and colonization (at least transitory) of the human body. Adhesion may increase the retention time of a probiotic and place bacteria and host surfaces (body fluids and epithelial cells) in close contact thus facilitating further probiotic activity

- Enhancement of the nonspecific and specific immune response of the host

- Production of antimicrobial substances and competition with pathogens for binding sites.

\section{Role of Probiotics in Human Health and Diseases}

Probiotics has a wide and varied range of clinical applications. They include lactose maldigestion, prevention and treatment of oral infection, dental caries, diarrhea, inflammatory bowel diseases, respiratory tract infections and allergic diseases. ${ }^{3}$ They are used in the treatment of irritable bowel syndrome and Helicobacter pylori infection. ${ }^{14}$ Apart from these applications, the role of probiotics also include antitumor effects, reduction of serum cholesterol and enhancement of vaccine responses. ${ }^{11}$ 


\section{PROBIOTICS AND MOUTH}

\section{Oral Microbiota as a Source of Probiotics}

Oral cavity provides the establishment of a great diversity of microbial species. It has been recently estimated that over 1000 bacterial species are present in the oral cavity. ${ }^{4}$ Bacteria reside in the mouth either in planktonic/free state or are finely integrated in oral biofilm on various oral surfaces. Oral biofilms are dynamically changing and develop increasingly complex structures as they mature. Bacteria in biofilms differ physiologically from their planktonic counterparts and tend to be much more resistant to environmental factors and antimicrobial agents. Saliva with its flow and with its various proteins having bactericidal and bacteriostatic activity is the essential medium in the mouth contributing to the microbial diversity.

Since probiotic species belong predominantly to the genera Lactobacillus and Bifidobacterium and because of the presence of 103-104 CFU/g lactobacilli found in the oral cavity, there could be some species/strains capable of exerting probiotic properties. ${ }^{5}$ Even though conclusive proof is yet to be obtained, some observations show that probiotic properties may indeed exist and reside in the oral cavity.

Adhesion of probiotics to the oral environment is necessary for the action of probiotics to take place. Saliva-mediated aggregation helps in this aspect, that is establishment of the probiotic bacteria in the oral cavity. The beneficial role of probiotics is because of their antagonistic action against pathogens. This is achieved by two mechanisms:

- Competition with pathogens for binding sites

- Production of antimicrobial substances.

Probiotics competing with pathogens for the binding sites are usually of similar strains without the pathogenicity. Production of antimicrobial substances is the more common method for antipathogenicity. These substances include (1) organic acids like lactic acid (2) hydrogen peroxide (3) bacteriocins (4) low molecular weight antimicrobial compound like reuterin (5) other agents like diacetyl, acetaldehyde and ethanol. ${ }^{7}$

Probiotics also has immunotimulatory function. They strengthen the epithelial barrier, initiate immune responses with the presence of ligands for toll like receptors in them. Stimulate interleukin- 8 and tumor necrosis factors-alpha (TNF- $\alpha$ ) secretion and has a positive effect on human $\beta$ defensin secretion by oral epithelial cells. ${ }^{10}$ The Flow Chart 1 shows the mechanism of action of probiotic in oral cavity.

\section{Probiotic Approach to Caries Management}

Streptococcus mutans is the main causative microorganism in caries development because of its ability to produce highly branched, water-insoluble glucan, mutan, which facilitates its establishment in the oral biofilm. ${ }^{13}$ Its acidogenic properties and rapid metabolism of sucrose, fructose and glucose generates low $\mathrm{pH}$ that induce caries. Moreover, elevated salivary counts of S. mutans are associated with higher caries risk and disease progression.

Various clinical trials with probiotics like Lactobacillus rhamnosus, Lactobacillus reuteri, Bifidobacterium DN-173010 has shown reduction in $S$. mutans count. ${ }^{6}$ This might be because of probiotic bacteria's ability to modify the composition of salivary pellicle by binding and degrading proteins important for bacterial adhesion thereby preventing adhesion of $S$. mutans to the oral biofilm.

A newer probiotic approach is the substitution strategy developed by Hillman et al. ${ }^{8}$ They have genetically modified S. mutans so that it no longer produces acid and displaces the wild strain of $S$. mutans from the ecological niche. Another method to remove pathogens is to develop targeted antimicrobials. Shi et al are developing targeting molecule which when attached with a killer molecule can eliminate the targeted molecule. ${ }^{9}$

Since lactobacilli themselves can be associated with caries progression, there is safety aspects to be considered. But the present strains commonly used, L. rhamnosus and $L$. reuteri does not ferment sucrose to produce acids and hence is relatively safe for prophylaxis. ${ }^{12}$

Proper delivery of probiotics to the target area is very important for which we rely upon vehicles. There are various vehicles available like milk, cheese, yogurt, ice cream, tablets, lozenges, etc. ${ }^{15}$ Each of these different vehicles deliver different strains of probiotic bacteria as seen in Table 1.

Flow Chart 1: Mechanism of action

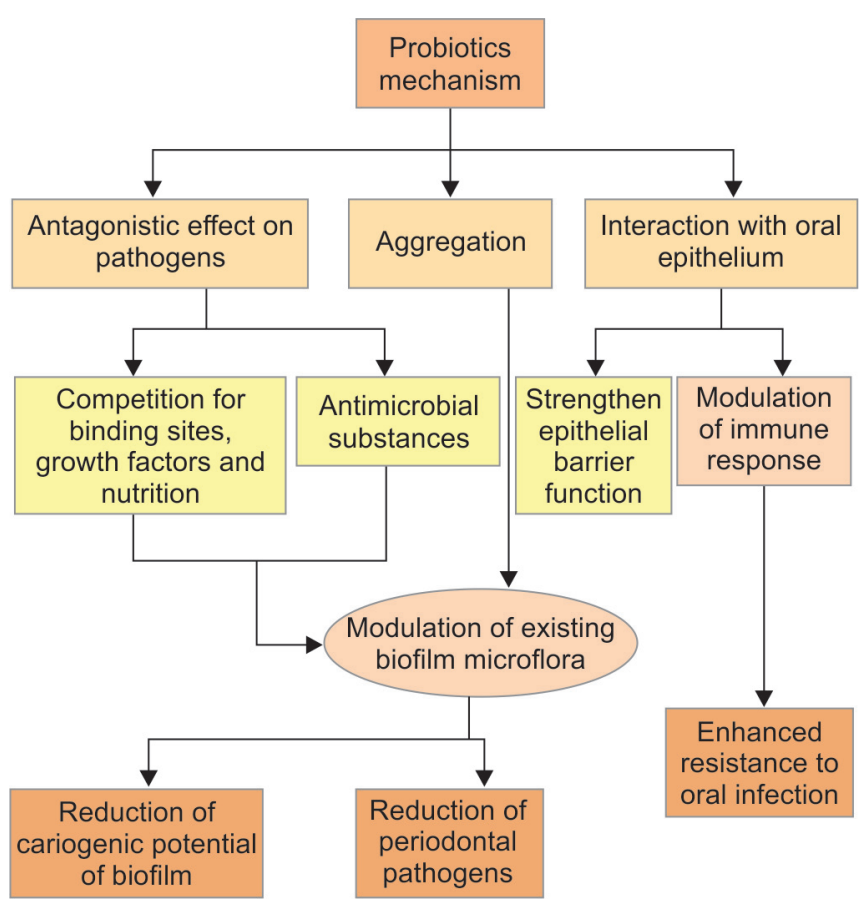


Table 1: Probiotic strains and their vehicles

\begin{tabular}{|c|c|c|c|c|}
\hline Probiotic strain & $\begin{array}{l}\text { Vehicle of } \\
\text { administration }\end{array}$ & $\begin{array}{l}\text { Duration of } \\
\text { administration }\end{array}$ & Clinical effectiveness & References \\
\hline L. rhamnosus GG & Milk & 7 months & $\begin{array}{l}\text { Less dental caries and lower S. mutans } \\
\text { levels }\end{array}$ & Nese et al \\
\hline $\begin{array}{l}\text { L. rhamnosus GG L rhamnosus } \\
\text { LC705 }\end{array}$ & Cheese & 3 weeks & $\begin{array}{l}\text { Reduction of levels of } S \text {. mutans, caries } \\
\text { risk reduction }\end{array}$ & Ahola et al \\
\hline Bifidobacterium DN-173 010 & Yogurt & 2 weeks & Reduction of salivary S. mutans & Çaglar et al \\
\hline B. lactis $\mathrm{Bb}-12$ & Ice cream & 10 days & Reduction of salivary S. mutans & Çaglar et al \\
\hline L. reuteri AICC 55730 & Chewing gum & 3 weeks & Reduction of salivary S. mutans & Çaglar et al \\
\hline
\end{tabular}

Apart from caries management other clinical applications of probiotics in relation to oral cavity include as follow:

- Periodontal disease

- Halitosis

- Candida infections

\section{CONCLUSION}

The oral cavity with a well maintained balance of the species and species interactions may be a potential source for health-promoting probiotic bacteria. On the other hand, daily intake of probiotic supplements may be used to control common oral and dental infections. The exact molecular mechanisms of the action of probiotics are still unclear. Furthermore, the dosage of probiotic administration in each indication needs to be defined. Even with many doubts a tremendous amount of research is going on in this field. The application of probiotic strategy may, in the not so distant future provide the end of new cavities in treated populations.

\section{REFERENCES}

1. Stamatova I, Meurman JH. Probiotics: Health benefits in the mouth. Am J Dent 2009 Dec;22(6):329-338.

2. Anderson $\mathrm{MH}$, Shi W. A Probiotic approach to caries management. Pediatr Dent 2006 Mar-Apr;28(2):151-153.

3. He X, Lux R, Kuramitsu HK, Anderson MH, Shi W. Achieving probiotic effects via modulating oral microbial ecology. Adv Dent Res 2009;21(1):53-56.

4. Keijser BJ, Zaura E, Huse SM JA, van der Vossen JM, Schuren FH, Montij RC. Pyrosequencing analysis of the oral microflora of healthy adults. J Dent Res 2008 Nov;87(11): 1016-1020.

5. Cortizo F. Probiotics and health: a new emerging modality in Biotherapeutics, Annal Dent Univ Malaya 1999;6(1):47-51.

6. Hasslöf P, Hedberg M, Twetman S, Stecksén-Blicks C. Growth inhibition of oral mutans streptococci and Candida by commercial probiotic lactobacilli: an in vitro study. BMC Oral Health 2010 Jul;10(1):18.

7. Agarwal E, Bajaj P, Guruprasad CN, Naik S, Pradeep AR. Probiotics: a novel step toward oral health. AOSR 2011;1(2): 108-115.

8. Hillman JD. Genetically modified Streptococcus mutans for the prevention of dental caries. Antonie Van Leeuwenhoek 2002 Aug;82(1-4):361-366.

9. Eckert R, QF, Yarbrough K, Anderson MH, Shi W. Adding selectivity to antimicrobial peptides against Pseudomonas spp. Antimicrobial Agents Chemother, 2006 Apr;50(4): 1480-1488.

10. Lee YK, Salminen S. Handbook of probiotics and prebiotics. 2nd ed. Hoboken, New Jersey: John Wiley and Sons; 2009.

11. Isolauri E. Probiotics in human disease. Am J Clin Nutr 2001 Jun;73(6):1142-1146.

12. Ahola AJ, Yli-Knuuttila $H$, Suomalainen $T$, Poussa $T$, Ahlstrom A. Short-term consumption of probiotic-containing cheese and its effect on dental caries risk factors. Arch Oral Biol 2002 Nov;47(11):799-804.

13. Adair SM, Xie Q. Antibacterial and probiotic approaches to caries management. Adv Dent Res 2009;21(1):87-89.

14. Gibson GR, Roberfroid MB. Dietary modulation of the human colonic microbiota: introducing the concept of prebiotics. J Nutrit 1995 Jun;125(6):1401-1412.

15. Parvez S, Malik KA, Kang SA, Kim HY. Probiotics and their fermented food products are beneficial for health Journal compilation 2006. J Applied Microbiol 2006 Jun;100(6): 1171-1185. 